\title{
INVESTIGATION OF POSSIBILITY TO UTILISE AGRICULTURAL WASTE IN GAS GENERATOR WITH PARAMETRIC PROCESS CONTROL
}

\author{
Peter Savinyh ${ }^{1}$, Andrew Palicynn ${ }^{2}$, Semjons Ivanovs ${ }^{3}$, Alexander Korotkov ${ }^{4}$ \\ ${ }^{1}$ North-East Agricultural Research Institute, Russia; ${ }^{2}$ Vologda State University, Russia; \\ ${ }^{3}$ Latvia University of Life Sciences and Technologies, Latvia; ${ }^{4}$ Andoga Ltd., Russia \\ semjons@apollo.lv
}

\begin{abstract}
Agriculture is one of the leaders in the production of waste at various stages of creation of the basic agricultural product. Economically attractive are those energy technologies, in the process of which both energy and new commercial products are produced (for example, organic or mineral fertilizers). The article deals with an option of energy processing of agricultural waste using a gas generator technology that makes it possible to obtain from the agricultural waste both thermal energy, gaseous fuel for technological needs, and concentrated mineral fertiliser. The patented innovation in the gas generation technology is application of parametric regulation of the gasification process. In the developed experimental prototype of the gas generator unit the thermal energy, obtained during the agricultural waste processing, can be used to dry a new portion of waste, going to gasification. Gaseous fuel, after cooling and purification, is sent to the internal combustion engine operating together with the electric generator or it is burned in a gas burner to produce thermal energy. A byproduct of thermal processing of agricultural waste is a concentrated mineral fertiliser - ash, the amount of which varies from 2.09 to $33 \%$, depending on the kind of fuel used for gasification. The innovative control system of the gas generator unit allows not only optimisation of the gas generation process, but also switching from one kind of fuel for gasification to another, without making structural changes to the gas generator. At onetype dynamic loading the response time to an external disturbance was $12 \mathrm{~s}$, with a maximum change in the rotation speed of the ICE crankshaft to $2310 \mathrm{rpm}$; and $8 \mathrm{~s}$, with a maximum change in the rotation speed of the ICE crankshaft to $2700 \mathrm{rpm}$.
\end{abstract}

Keywords: agriculture, waste, gas, generator, process.

\section{Introduction}

The problem of agricultural waste utilisation is currently quite acute in the light of increased energy efficiency of production and toughening the requirements of environmental legislation [1-2]. To solve it, specialists develop and research several strategic directions, the key ones being a reduced amount of waste produced per unit of the basic agricultural product due to the introduction of modern technologies and machine system, as well as waste recycling. Waste is an integral part of the technological process of production of the basic agricultural products. For example, it is straw in the production of cereals, or animal manure in the production of milk and meat. Due to the specificity of agricultural production (the use of animals and plants in the technological processes), this technology cannot be absolutely waste-free. Reduction in the amount of waste in the production also has a limit to which contemporary manufacturers, using the traditional production technologies, have come close. As a result of this, energy technologies for waste processing are of practical interest during which both energy and new products are produced (for example, organic or mineral fertilisers).

Today the most promising is the biogas technology of the agricultural waste processing. In contrast to the conventional technologies (composting, express composting, vermicultivation, etc.), the biogas technology of the agricultural waste processing allows limited control and maintenance of optimal conditions for the technological process, the by-product of which are the released combustible gases (biogas).

Despite the obvious advantages, the biogas technology of the agricultural waste processing has some disadvantages. These may be:

- large mass-dimensional characteristics of the technological equipment involved in processing;

- a long-time period of the technological cycle of processing (depending on the technology used, from 10 to 50 days).

An alternative to the biogas technology can be thermal processing of waste using gas generation technologies. The technological process proceeds at high temperatures, of the order of $800-1000{ }^{\circ} \mathrm{C}$, which ensures sterilisation of the final product from the pathogenic microflora and weed seeds, accompanied by the release of thermal energy and combustible generator gas. The advantages of this technology include: 
- small mass-dimensional characteristics of the technological equipment, which ensures mobility (waste disposal is carried out where it is necessary, or where energy is needed);

- prompt obtaining of thermal energy and generator gas (the gas generator is set to an operating mode within 10-15 minutes);

- when using a gas generator, there are obtained not only thermal energy and generator gas, but also concentrated mineral fertilizer (ash).

A literature review and analysis of international patent databases concerning the energy technologies for waste processing and the energetic use of the local biological resources showed that there have not occurred any significant, "revolutionary" technical and technological changes in the designs of the gas generating units since the middle of the 20th century. Besides, there is observed an "evolution" of elements and systems of the gas generating units, in terms of the use of modern structural materials (for example, the use of alloy steels instead of the conventional ones), mechanisation and automation of the preparation, loading and metered supply of fuel for gasification, and so on. It should be remarked that one of the significant innovations in the design of the gas generating units was the control system of the gas generator operating in conjunction with the internal combustion engine (ICE) and the electric generator, using an industrial controller developed by a group of American inventors led by James Matthew Mason. It found practical implementation in the gas generator designs of the Gasifier Experimenters Kit (the GEK) [3-4]. The research of gas generators is also being conducted in India, China, and several countries of the European Union, including the works not only of a generalising - theoretical, but also experimental nature. [5-6].

As the experimental studies of the gas generator units show, the process of gasification of the organic materials is a rather complicated, multi-factor chemical process of destruction and partial oxidation of complex multicomponent compounds and their chemical bonds. As a result of this, simple chemical compounds are formed $\left(\mathrm{CO}_{2}, \mathrm{CO}, \mathrm{H}_{2}, \mathrm{CH}_{4}\right.$, etc.), and a certain amount of thermal energy is released, since the total heat balance of the process is positive. To the main factors that have a significant impact upon the gasification of organic materials we can relate: the selected type of the gasification process (direct, reversed or transverse), the design parameters of the gas generator, the kind of fuel, the temperature along the working zones of the gas generator, the method of supply and the rate of expiration of the air stream from the tuyere (air jet) into the reaction zone of the gas generator $[5 ; 9-10]$.

\section{Materials and methods}

Analysis of the results of the research experiments on joint operation of the gas generator and the gas consumer, which was the ICE, made it possible to formulate the concept of a parametric gas generator with the control of the working process in the plane of the tuyere belt [11].

The design parameters of gas generators of the conventional designs are calculated based on the conditions of maximum production of the generator gas for the consumer. Yet, the consumption and, consequently, production of gas in the gas generator during its operation varies to a significant degree. This leads to a decreased energy value of the unit volume of the generator gas due to decreased air blast velocity through the tuyeres, because the volume of the air sucked by the consumer through the gas generator decreases, and the total passage section of the tuyeres remains unchanged. As a result, the temperature in the reaction zone of the gas generator decreases, its active area decreases, and the rates of reduction reactions decrease.

Figure 1 shows a general view of the gas generator, and Fig. 2 presents the distribution pattern of the air blast from the tuyeres of the gas generator, using the principle of parametric regulation of the working process in the plane of the tuyere belt.

The gas generator is operating according to the principle of parametric regulation of the working process in the plane of the tuyere belt. The gas generator differs from the gas generators of conventional designs by the presence of an individual air supply to each tuyere. This allows not only to increase the efficiency of the gasification process in the gas generator due to heating the air supplied to the reaction area through the tuyeres, but also, by using a system of electromagnetic valves, to change the number of the activated tuyeres, maintaining constant expiration speed of the air blast from the tuyere in various modes of operation of the gas generator. In order to maintain constant temperature and working area of the reaction 
zone at transient (non-nominal) modes of operation of the gas generator, the operation of the blowing tuyeres is alternated. The pulse operation mode of the blowing tuyeres is also possible. To improve the dynamic characteristics of the internal combustion engine during the transient modes of operation, the gas generator is equipped with an afterburner air circuit.

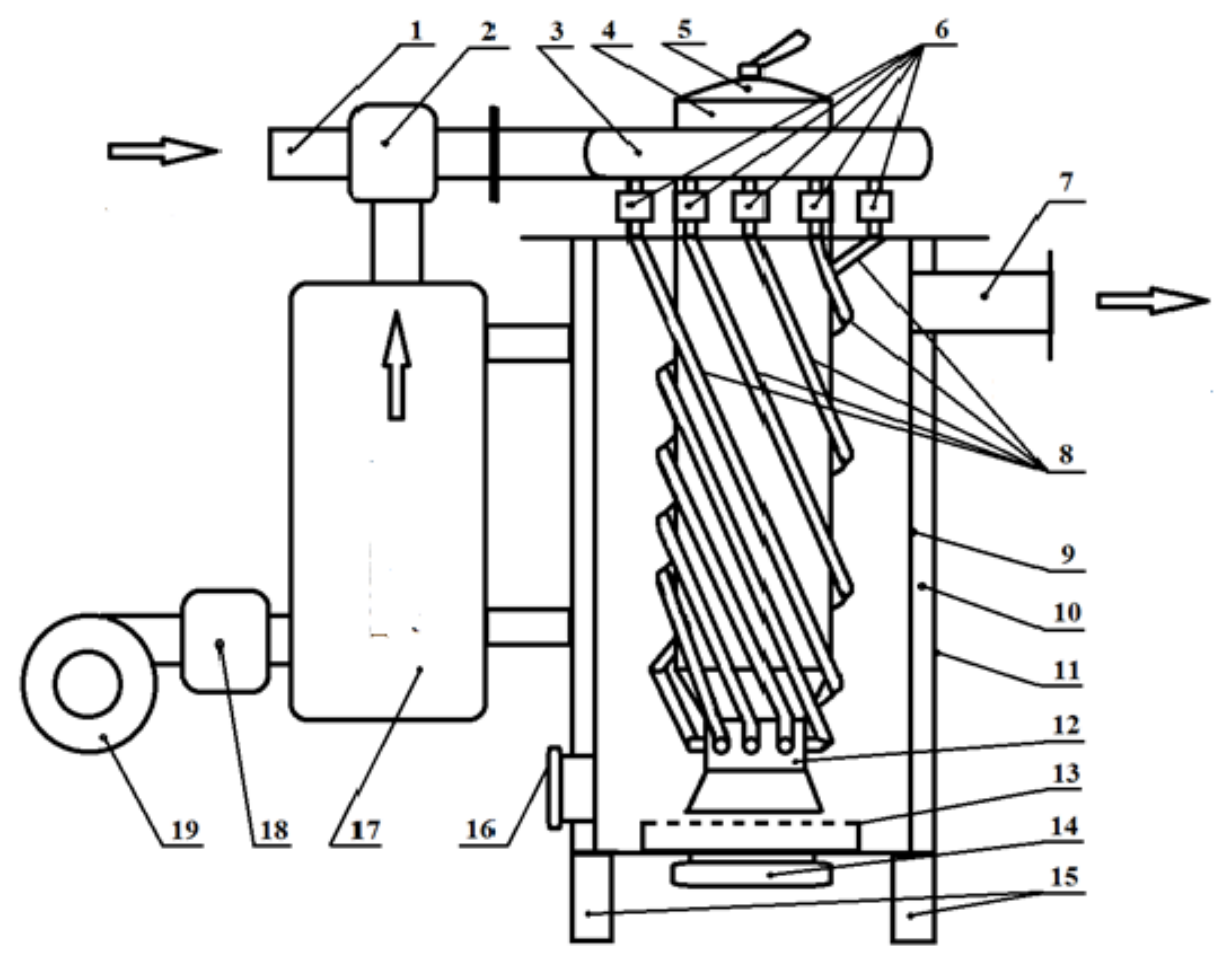

Fig. 1. General view of the gas generator: 1 - an air blast pipe; 2 - a three-way electromagnetic valve; 3 - an air collector; 4 - a gasification chamber; 5 - the loading hatch with a locking mechanism; 6 - a system of electromagnetic valves; 7 - a gas outlet; 8 -individual tuyere blow tubes; 9 - the gas tank; 10 - a thermal insulation encasement; 11 - an external protective cover; 12 - the area of the tuyere belt; 13 - the ash pan; 14 - the ash hatch; 15 - supports; 16 - a technological hatch;

17 - the air tank; 18 - a reverse valve; 19 - a blower fan

a)

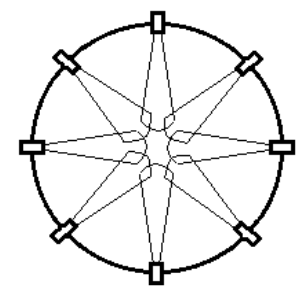

b)

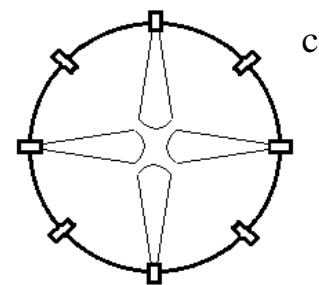

c)

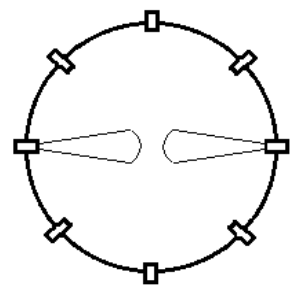

Fig. 2. Distribution pattern of the air blast: $a-$ the nominal mode (the ICE is running at full power, maximum generator gas consumption); $b-1 / 2$ of the nominal mode; $\mathrm{c}-$ the mode of idle running of the ICE

Application of parametric regulation of the working process in the plane of the tuyere belt in the generator allows:

- to adjust the operating mode of the gas generator unit, depending on the type and physicomechanical characteristics of the fuel (agricultural waste) going to gasification;

- to maintain optimum temperature in the plane of the reaction zone of the gas generator, which positively affects the homogeneity of the composition and energy value of a unit volume of the produced generator gas;

- to reduce the duration of the transient processes in the system ,the gas generator unit - the ICE" at the expense of an afterburner circuit, with an excess pressure at the inlet of the gas 
generator, thereby improving the dynamic characteristics of the ICE at a sharp increase in its load.

The proposed technology was practically implemented in an experimental gas generator unit manufactured at the Andoga Ltd. repair and production facilities. A general view of the gas generator is shown in Fig. 3, and the torch (flame) of the generator gas is shown in Figure 4. Processing of agricultural waste was carried out in a gas generator operating according to the inverted type of the gasification process, with a parametric control of the blowing tuyeres in the plane of the tuyere belt. The controller for controlling the operation of the electromagnetic valves and the blower fan is assembled on the Arduino platform. In the experiments, the AB-4-O/230-M1 power station with a two-cylinder four-stroke ICE and a UD-25-M1 for air cooling, as well as a gas burner were used as the generator gas consumers.

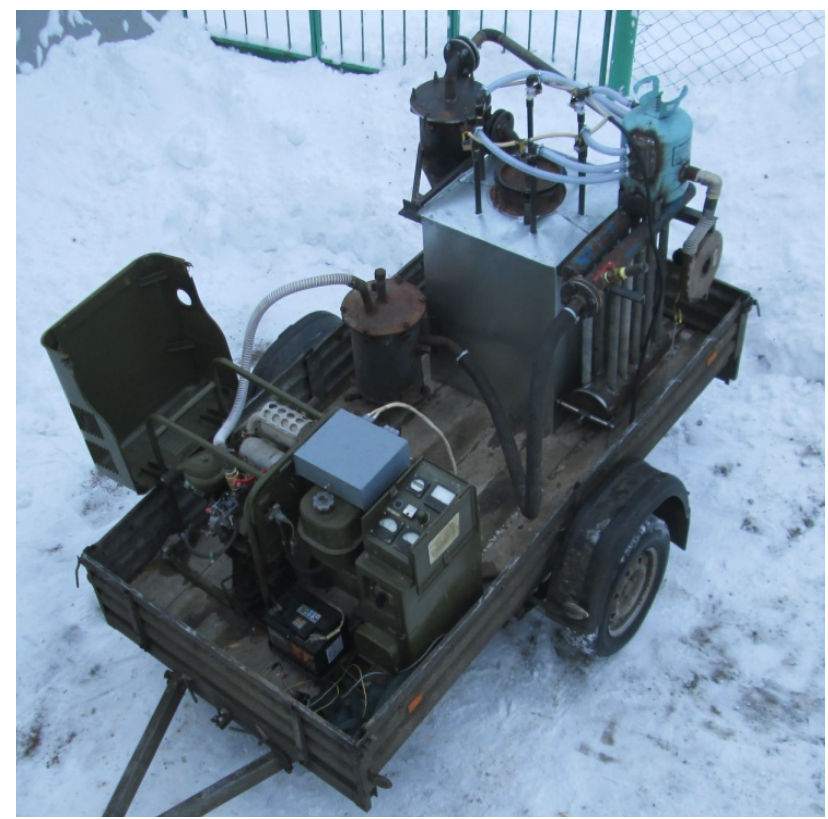

Fig. 3. General view of the gas generator

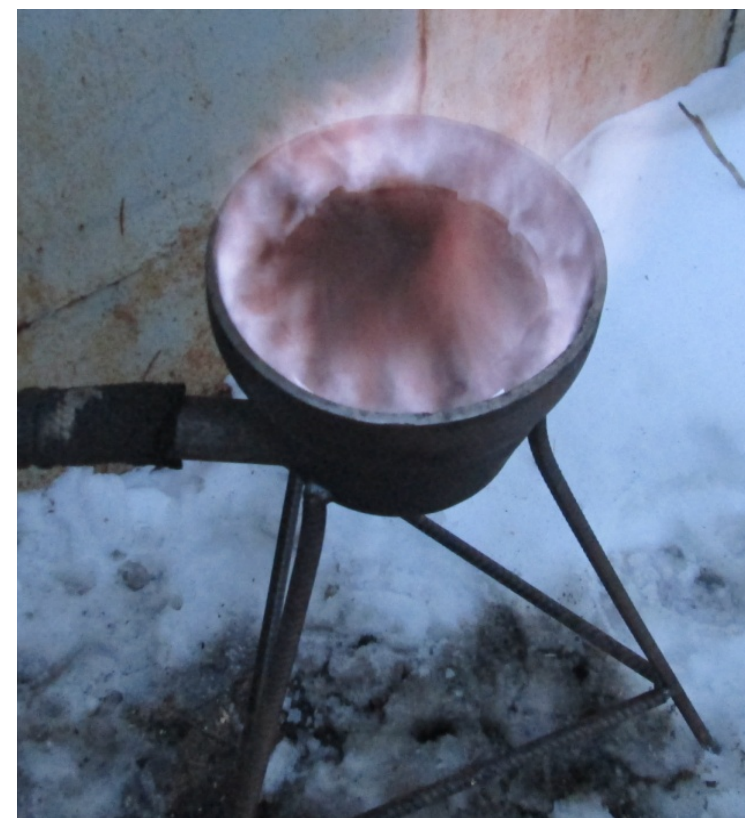

Fig. 4. Torch (flame) of the gas generator

Research in approbation of the control modes of the gas generator was carried out in a specialised laboratory of the engineering department of the Vologda State University.

The investigations studied the impact of the gas generator control modes upon the dynamic characteristics of the internal combustion engine of a power plant. The operating parameters of the internal combustion engine were controlled by a measuring system based on a personal computer with an optical tachometer DO-03-02 and an electronic oscilloscope DiaMag 2.

The moisture and ash content of the fuels (agricultural waste), used in the experiments, are determined by standard methods in the Vologodsky testing laboratory, which has state accreditation. The used methods and measuring equipment make it possible to determine the mass moisture content in the sample with an accuracy of $\pm 0.8 \%$, and the ash content $\pm 0.3 \%$.

\section{Results and discussion}

The research conducted with the experimental gas generator unit pointed to the need for individual adjustment of the operation mode of the blower tuyeres of the gas generator and the blower fan, depending on the kind, humidity, physical and mechanical characteristics of the fuels (agricultural waste) going to gasification, as well as the need for their preliminary preparation before use. The research results of fuels used in the experiments are presented in Table 1. In the experiments the deviation of the measured parameters did not exceed $3.7 \%$.

To use agricultural waste as a fuel in the gas generator, it is necessary first of all to reduce the moisture content in them to $35-40 \%$. This can be done by drying with the hot exhaust gases of the internal combustion engine (ICE) and warm air from the cooling system of the internal combustion 
engine and the generator gas through a layer of the prepared fuel. In the experiments the removal of the excess moisture from the fuel going to gasification was carried out in the drying chamber.

Table 1

Basic characteristics of fuels (agricultural waste) used in the experiments

\begin{tabular}{|c|c|c|}
\hline Agricultural waste & Mass content of moisture, \% & Ash, \% \\
\hline Horse manure & 83.7 & 20.0 \\
\hline Cow manure & 85.0 & 18.0 \\
\hline Grassroot peat & 64.8 & 33.0 \\
\hline Peat transitional & 58.7 & 21.5 \\
\hline Wood chips (pine) & 67.6 & 3.0 \\
\hline Feed barley & 9.36 & 2.09 \\
\hline Barley straw & 52.57 & 10.15 \\
\hline
\end{tabular}

The choice of the optimal mode of operation of the electromagnetic valves and the blower fan has a significant impact upon the quality composition of the produced gas and its energy value due to the temperature optimisation in the reaction zone of the gas generator unit. This, in its turn, determines the dynamic characteristics (the response time to an external disturbance) of the internal combustion engine (ICE) when it is loaded.

Fig. 5 and 6 present fragments of tachograms of the tests on the operation of the ICE of the power plant using the generator gas, without control of the electromagnetic valves (the valves are open), the blower fan is turned off (Fig. 5), and with the control mode of the electromagnetic valves and the blower fan turned on (Fig. 6). In both cases, the loading mode of the generator is identical. Under dynamic loading (the active load elements), the response time to an external disturbance was: Fig. 5 $120 \mathrm{~s}$ with a maximum change in the engine rotation speed from $3100 \mathrm{rpm}$ to $2310 \mathrm{rpm}$. And in Fig. 6 $-8 \mathrm{~s}$ with a maximum change in the engine rotation speed from $3100 \mathrm{rpm}$ to $2700 \mathrm{rpm}$. In these experiments wood chips were used as a fuel for the production of the generator gas.

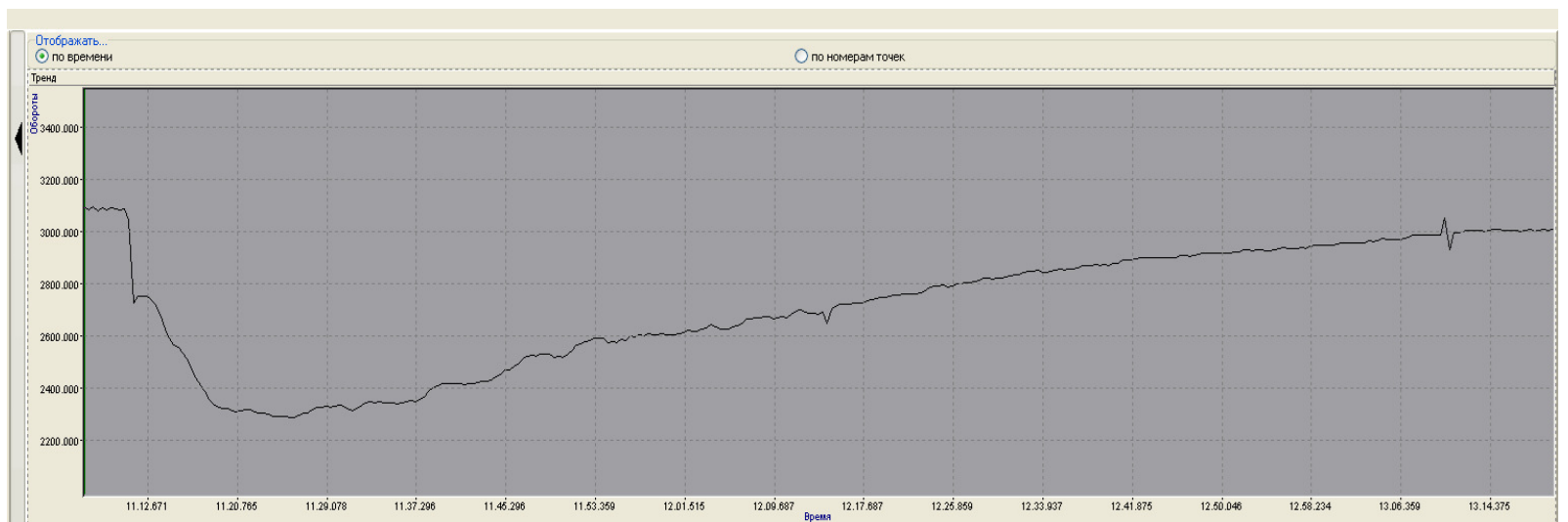

Fig. 5. Dynamics of the internal combustion engine when working on generator gas, without the gas generator control

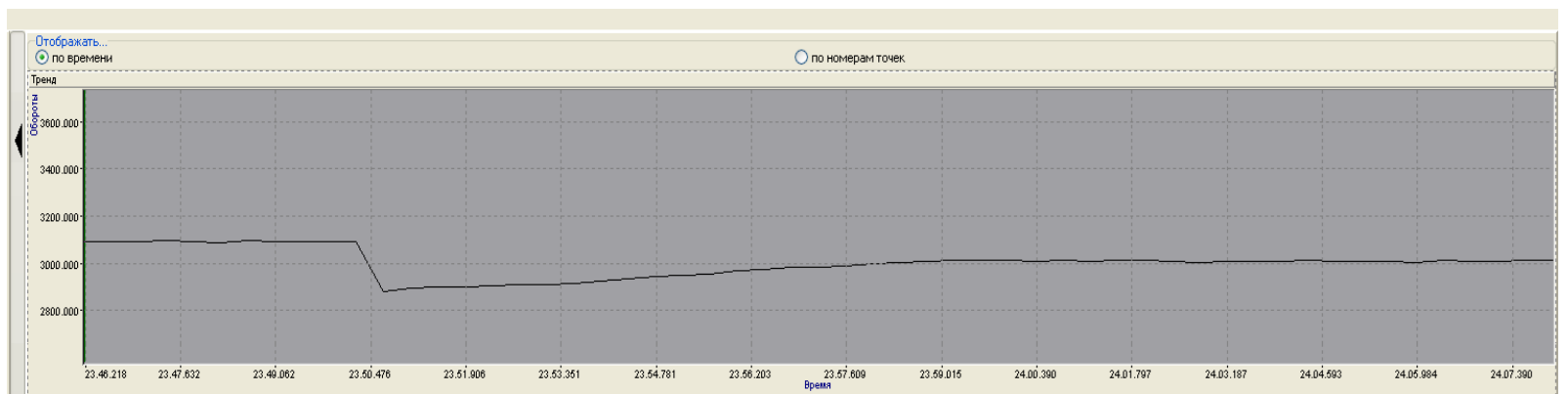

Fig. 6. Dynamics of the internal combustion engine when working on generator gas, using the control mode of the gas generator 


\section{Conclusions}

1. The gas generator technologies for energy processing of agricultural waste can be quite competitive with the conventional biogas technologies due to their mobility and the speed of the waste processing.

2. The innovative control system of the gas generator unit allows not only optimisation of the gas generation process, but also switching from one kind of fuel for gasification to another without making structural changes to the gas generator. This extends the functionality of the gas generator unit in processing agricultural waste.

3. Agricultural waste, before its use in the gas generator unit, requires preliminary preparation, as it contains a significant amount of moisture. This can be done by drying with the hot exhaust gases of the internal combustion engine and with the warm air from the cooling system of the internal combustion engine and the generator gas through a layer of the fuel to be prepared.

4. A by-product of thermal processing of agricultural waste is a concentrated mineral fertiliser - ash, the amount of which varies from 2.09 to $33 \%$, depending on the kind of fuel used for gasification.

5. At one-type dynamic loading (the active load elements), the response time to an external disturbance was $12 \mathrm{~s}$, with a maximum change in the rotation speed of the ICE crankshaft to $2310 \mathrm{rpm}$; and $8 \mathrm{~s}$, with a maximum change in the rotation speed of the ICE crankshaft to $2700 \mathrm{rpm}$. The conducted research allows drawing a conclusion about the improvement of the dynamic characteristics of the ICE, during its operation.

\section{References}

[1] Santos Dalólio F., da Silva J.N., Carneiro de Oliveira A.C., Ferreira Tinôco I.D.F., Christiam Barbosa R., Resende M.D.O., Teixeira Albino L.F., Teixeira Coelho S. Poultry litter as biomass energy: A review and future perspectives. Renewable and Sustainable Energy Reviews, Vol. 76, 2017, pp. 941-949.

[2] Roy P.C., Datta A., Chakraborty N. An assessment of different biomass feedstocks in a downdraft gasifier for engine application. Fuel, Vol. 106, 2013, pp. 864-868.

[3] Gasifier Experimenters Kit (the GEK, USA), Available at: www.gekgasifier.com

[4] James Matthew Mason. System and method for downdraft gasification. Patent US 20110023363A1, United States. Pub. Date: Feb. 3, 2011.

[5] Thomas B. Reed. Generator gas. The Swedish Experience - Gas 1939-1945. Biomass Energy Foundation, 1998. 334 p.

[6] Chris Higman, Maarten van der Burgt Gasification. Gulf Professional Publishing is an imprint of Elsevier Science. Elsevier Science (USA), 2003. 391 p. ISBN 0-7506-7707-4.

[7] Basu P. Biomass gasification and pyrolysis: Practical design and theory. Elsevier, 2010. 364 p.

[8] Sharma A K Modeling and simulation of a downdraft biomass gasifier 1 model development and validation. Ener. Convers. Manag., 52(2), 2011. pp. 1386-1396.

[9] Wang Y., Kinoshita C. Kinetic model of biomass gasification. Solar Ener,,51(1), 1993. pp. 19-25.

[10] Yucel O and Hastaoglu M A. Kinetic modeling and simulation of throated downdraft gasifier. Fuel Process Technol., 144, 2016. pp. 45-154.

[11] Острецов В.Н., Зубакин А.С., Палицын А.В., Коротков А.Н. Газогенератор (Generator gas). Патент RU 2555486, 2015. (In Russian). 